\title{
THE INTERNATIONAL JOURNAL OF BAHAMIAN STUDIES
}

\section{Volume 17, 2011 - Issues 1 \& 2}

Research is a hallmark of the university and at The College of The Bahamas our faculty, staff and students continue their engagement in a number of research projects.

The International Journal of Bahamian Studies, a research publication of The College of The Bahamas, is a medium which spotlights some of that research and is now at its 17th volume. As has become the tradition, the journal is published during International Open Access Week as The College's contribution to the movement for making scholarly research available to all. Further, digitizing the journal's back issues has been useful in that the articles are accessible to scholars all over the world, and at no cost.

This year marks the first time that two issues will be published. The first issue constitutes a groundbreaking bibliography of Caribbean art and classical music. Such a compilation has never been published before. The two faculty members conducting this research, Dr. Christine Gangelhoff, from the Music Department, and Ms. Cathleen LeGrand, formerly with The College's Library and Instructional Media Services Department, received a research grant from The College to assist them in their work. The publication of the bibliography is exciting not only because it is completely novel but because the authors have included video and audio links in the articles, offering the reader a multimedia experience.

The second issue includes science-related articles, exclusively. These articles have been written by scholars from The Bahamas as well as overseas, in keeping with the journal's international orientation. Articles focus on topics of importance to the Bahamian scientific community and the community at large: the invasion of the lionfish into Bahamian waters and the outbreak of Dengue fever in the summer of 2011.

This year is the 40th anniversary of the existence of The College's Gerace Research Centre (GRC) at San Salvador Island, and I am very pleased that student researchers at the Centre have chosen to publish their research findings in our journal. It is equally pleasing that the autobiography of GRC founder, Dr. Don Gerace, has been included in the Book Review section.

We at The College continue to be proud of this journal of scholarly research and congratulations are in order for the publication of this 17 th volume.

Betsy Vogel-Boze, Ph.D.

https://doi.org/10.15362/ijbs.v17i2.158 